\title{
Outcome of CBV (Carmustine, Cyclophosphamide, Etoposide) Conditioning Regimen for Autologous Stem Cell Transplant in Lymphoma: A Retrospective Study from a Tertiary Cancer Center in South India
}

\author{
Narendran Krishnamoorthi ${ }^{1}$ Bhanu Prakash ${ }^{1}$ Dhanraju KM ${ }^{1}$ Chinmaya Kumar Pani ${ }^{1}$ Malliha Ram ${ }^{1}$ \\ Kalpana Rajesh ${ }^{1}$ Biswajit Dubashi ${ }^{1}$ Prasanth Ganesan ${ }^{10}$ Smita Kayal ${ }^{10}$
}

${ }^{1}$ Department of Medical Oncology, Jawaharlal Institute of Postgraduate Medical Education and Research (JIPMER), Dhanvantari Nagar, Pondicherry, India

Ind J Med Paediatr Oncol
Address for correspondence Smita Kayal, MD, DM, Department of Medical Oncology, Regional Cancer Centre, JIPMER, Dhanvantari Nagar, Puducherry 605006, India (e-mail: kayalsmita@gmail.com).

\begin{abstract}
Keywords

- CBV conditioning regimen

- autologous stem cell transplant

- Hodgkin lymphoma

- non-Hodgkin lymphoma
\end{abstract}

Background In autologous stem cell transplant (ASCT) for lymphomas, no standard conditioning regimen has been defined so far. Thus, the choice is guided by the center's familiarity and experience with a particular regimen.

Objective To determine the response, toxicity, and survival outcomes in lymphoma patients who underwent ASCT with CBV (cyclophosphamide, carmustine, and etoposide) conditioning regimen.

Materials and Methods Between January 2013 and May 2019, 45 consecutive lymphoma patients who had ASCT with CBV conditioning regimen were included in this retrospective study. CBV consisted of cyclophosphamide $\left(1.5 \mathrm{~g} / \mathrm{m}^{2} /\right.$ day $\times 4$ days), carmustine $\left(300 \mathrm{mg} / \mathrm{m}^{2} \times 1\right.$ day), and etoposide $\left(125 \mathrm{mg} / \mathrm{m}^{2}\right.$ twice daily $\times 3$ days). Baseline characteristics, pre transplant response, apheresis, post-transplant toxicities, post-transplant response, and survival outcomes were collected. Endpoints were toxicity, response, event-free survival (EFS), and overall survival (OS).

Results The median age was 30 (range: 6-64) years. Diagnosis was Hodgkin lymphoma (HL) in 26 (58\%) and non-Hodgkin lymphoma (NHL) in 19 (42\%). Fortythree patients (95\%) had chemosensitive disease; 22(49\%) in CR, and 21 (46\%) in PR. The median CD34 was $2.95 \times 10^{6} / \mathrm{kg}$ (range: $0.9-9.56$ ). The median time to neutrophil engraftment was 11 days (9-23) and 13 (8-36) days for platelets. All patients had febrile neutropenia, clinically and/or microbiologically documented infection was seen in $75 \%$ of patients. The most common grade $3 / 4$ toxicities were mucositis $(n=4,9 \%)$, diarrhea $(n=4,9 \%)$, and nausea/vomiting $(n=2,4 \%)$. The average days of hospitalization was 18 (range: $10-37)$. Day 100 mortality was $6.6 \%(n=3)$. The median follow-up was 44.8 months. The median EFS for the entire cohort was 23.8 months; for $\mathrm{HL}$, the median EFS was not reached, and for NHL, it was 7.97 months ( $95 \%$ confidence interval
DOI https://doi.org/ 10.1055/s-0041-1740134. ISSN 0971-5851.
(C) 2022. Indian Society of Medical and Paediatric Oncology. All rights reserved.

This is an open access article published by Thieme under the terms of the Creative Commons Attribution-NonDerivative-NonCommercial-License, permitting copying and reproduction so long as the original work is given appropriate credit. Contents may not be used for commercial purposes, or adapted, remixed, transformed or built upon. (https://creativecommons.org/ licenses/by-nc-nd/4.0/)

Thieme Medical and Scientific Publishers Pvt. Ltd., A-12, 2nd Floor, Sector 2, Noida-201301 UP, India 
[CI]: 1.57-14.37). The median OS for the entire cohort and for HL was not reached; for $\mathrm{NHL}$, it was 24.3 months (95\% Cl: 0.56-48.11).

Conclusion CBV conditioning regimen was well tolerated with low grade $3 / 4$ toxicities and efficacy comparable to literature data.

\section{Introduction}

High-dose chemotherapy (HDC) followed by autologous stem cell transplant (ASCT) is the current standard of care for relapsed/refractory lymphoma. ${ }^{1,2}$ Several HDC regimens with varying drug combinations, with or without total body irradiation (TBI), have been in use as the conditioning protocol in autologous transplant of lymphomas. Most have shown similar efficacy but different toxicity profiles. Compared to chemotherapy-TBI regimens, chemotherapy-only regimens have demonstrated superiority in terms of disease-free survival (DFS), overall survival (OS), and lesser toxicity. ${ }^{3,4}$ Commonly used HDC regimens in ASCT for lymphoma include BEAM (BCNU, etoposide, cytarabine, and melphalan), BEAC (BCNU, etoposide, cytarabine, and cyclophosphamide), CBV (cyclophosphamide, BCNU, and etoposide), and LACE (lomustine, etoposide, cytarabine, and cyclophosphamide), ${ }^{5-9}$ but no prospective randomized study has been done so far comparing these regimens. Most of the retrospective studies comparing various HDC regimens have shown variability in toxicity, and some have reported differences in disease outcomes. $^{3,10-16}$

In our center, CBV has been the commonest conditioning regimen used for autologous transplant in lymphomas. Unfortunately, data regarding the use of CBV are scant in contemporary published literature, and there are no reports on the use of CBV conditioning from India. This study has retrospectively analyzed the toxicity profile, engraftment kinetics, and survival outcomes of lymphoma patients who have undergone ASCT using a CBV conditioning regimen.

\section{Methodology}

\section{Patient Population}

From January 2013 to May 2019, all consecutive histologyproven relapsed or refractory Hodgkin lymphoma (HL) and non-Hodgkin lymphoma (NHL) patients, who had a complete or partial response to salvage chemotherapy and underwent ASCT at our center, with CBV conditioning regimen were included in this retrospective study. Patients who received other conditioning regimen were excluded from the study.

We collected the data for baseline characteristics, pretransplant response, apheresis, post-transplant toxicities, post-transplant response, and survival outcomes from medical records maintained in the department. Endpoints were toxicity, post-transplant response, event-free survival (EFS), and overall survival (OS).

\section{Pre-Transplant Assessment}

Relapsed or refractory lymphoma was treated with 3 to 4 cycles of first- or second-line salvage chemotherapy depending on their primary diagnosis and previous treatment history. Post salvage response assessment was done with either contrast-enhanced computed tomography (CECT) scan or positron emission tomography and computed tomography (PET-CT) scan. Pre-transplant chemosensitivity was defined as either complete or partial response following salvage therapy. Evaluation was done for organ functions (renal, hepatic, cardiac, and pulmonary) and general fitness as per the department protocol for all patients prior to transplant.

\section{Stem Cell Mobilization, Collection, and Cryopreservation}

Peripheral blood (PB) stem cell mobilization was done with GCSF $5 \mu \mathrm{g} / \mathrm{kg}$ twice daily for 4 days. One day prior to apheresis, on the fourth day of mobilization, PB CD34 enumeration was done. Plerixafor was used 12 hours before apheresis if the PB CD34 was $<20$ cells $/ \mathrm{mm}^{3}$ or as per physician's discretion based on the baseline risk factors for poor mobilization. All patients had undergone peripheral blood stem cell (PBSC) harvest by apheresis, and stem cell enumeration was done at the end of harvest. PBSC collected were volume depleted and cryopreserved using $10 \%$ of dimethyl sulfoxide (DMSO) and autologous plasma at $-80^{\circ} \mathrm{C}$ until day 0 (day of stem cell reinfusion).

\section{Conditioning Regimen}

$\mathrm{CBV}$ conditioning regimen was given over a period of 6 days in the following schedule: BCNU (carmustine) $300 \mathrm{mg} / \mathrm{m}^{2}$ intravenous (iv) over 2 hours on D-6, cyclophosphamide $1.5 \mathrm{~g} / \mathrm{m}^{2} /$ day i.v. over 2 hours on D-6 to D-3, mesna $120 \%$ of cyclophosphamide dose as i.v. infusion over 24 hours on D-6 to D-3, and $40 \%$ of cyclophosphamide dose as i.v. infusion over 12 hours on D-2, etoposide $125 \mathrm{mg} / \mathrm{m}^{2} /$ dose i.v. over 1 hour 12 th hourly on D-6 to D-4. The above CBV schedule is considered as CBV (low) compared to the older regimen CBV (high), which used carmustine at $600 \mathrm{mg} / \mathrm{m}^{2} .{ }^{10,11}$

\section{Supportive Care}

All patients received G-CSF $5 \mu \mathrm{g} / \mathrm{kg} /$ day subcutaneous (s.c.) starting on day +1 after stem cell infusion until the absolute neutrophil count (ANC) was greater than $0.5 \times 10^{9} / \mathrm{L}$ for least 3 days. ${ }^{17,18}$ Irradiated packed red cell concentrates and platelet concentrates were given to keep hemoglobin $>8.0$ $\mathrm{g} / \mathrm{dL}$ and platelet count $>20 \times 10^{9} / \mathrm{L}$, respectively. Oral fluconazole and acyclovir were started from day 1 as antifungal 
and antiviral prophylaxis, respectively. Routine antibacterial prophylaxis was not given. Total parenteral nutrition (TPN) was administered in patients who developed grade 3-4 mucositis and in any grade mucositis with decreased food intake. Febrile neutropenia was managed as per the department antibiotic policy.

\section{Study Definitions}

Time to neutrophil engraftment was defined as the first of three consecutive days with an absolute neutrophil count of $\geq 0.5 \times 10^{9} /$ L. $^{19,20}$ Time to platelet engraftment was defined as the first of three consecutive days when the platelet count

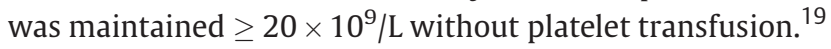
Engraftment syndrome was defined by the presence of noninfectious fever and one other symptom (i.e., skin involvement, diarrhea, or pulmonary manifestations) during the peri-engraftment period. ${ }^{21}$ Regimen-related organ toxicities, evaluated in the first 100 days, were graded using the Seattle criteria, whereas mucositis and chemotherapy-induced nausea and vomiting (CINV) were graded using the National Cancer Institute Common Terminology Criteria For Adverse Events (NCI CTCAE) v4.0. ${ }^{22,23}$ The length of hospital stay (LOS) was defined as the time from the day of infusion of stem cell product (Day 0) to the day of hospital discharge. Transplant-related mortality (TRM) was defined as any death not related to relapse or disease progression during the first 100 days after the transplant. EFS (event-free survival) was defined as the time interval from the date of the transplant to disease progression, relapse, or death due to any cause. Overall survival (OS) was defined as the time from transplant to death due to any cause or date of the last follow-up.

\section{Statistical Analysis}

Descriptive statistics were used to summarize baseline disease features, pre-transplant disease status, patient characteristics, and post-transplant outcomes. Estimation of EFS and OS was done using the Kaplan-Meier method and compared using log rank test. Data were censored on 31 March 2020 for survival analysis. IBM SPSS Statistics for Windows, Version 19.0. Armonk, NY: IBM was used for analysis.

\section{Ethics}

The procedures followed were in accordance with the ethical standards of the responsible committee on human experimentation and with the Helsinki Declaration of 1964, as revised in 2013. The study was approved by the Institute Ethics committee (no. JIP/IEC/2016/30/979, dated 23.10.2016), and waiver of informed patient consent was granted.

\section{Results}

\section{Baseline Characteristics and Pre-Transplant Data}

During the study period, 45 patients (28 males and 17 females) underwent autologous transplant with a CBV conditioning regimen for refractory/relapsed lymphoma. The median age was 30 years (range: 6-64). Diagnosis was HL in 26 patients (58\%) and NHL in 19 patients (42\%). Of the 45 patients, 28 (62\%) had relapsed after their primary treat- ment, and 15 (35\%) had refractory disease. The median time from diagnosis to transplant was 19 months, and median lines of previous therapy were two. As a part of pretransplant response assessment, PET CT and CECT was done in 22 (49\%) and 23 (51\%) patients, respectively. Among the 45 patients, 43 (96\%) had chemosensitive disease (either complete response [CR] or partial response [PR]). All patients had ECOG (Eastern Cooperative Oncology Group) performance status of 1 before transplant baseline clinical characteristics, and pretransplant disease status is shown in - Table $\mathbf{1}$.

\section{Apheresis}

For 45 patients, a total of 70 apheresis procedures were done. The median number of apheresis done was 2 (range: $1-3$ ); for HL was 2 (range: $1-3$ ), and for NHL was 1 (range: $1-3$ ). The median CD34 cells $/ \mathrm{kg}$ for entire cohort was $2.95 \times 10^{6} / \mathrm{kg}$ (range: 0.9-9.56), for HL $2.99 \times 10^{6}$ (range: 0.90-7.3), and for NHL $2.90 \times 10^{6}$ (range: 1.77-9.56). The median total MNC/kg for the entire cohort was $6.04 \times 10^{8}$ (range: $2-27$ ), for $\mathrm{HL}$ $6.03 \times 10^{8}$ (range: $2-27$ ), and for NHL $6.35 \times 10^{8}$ (range: $4-$ 20). All PBSC apheresis products were cryopreserved and stored at $-80^{\circ} \mathrm{C}$ until the day of infusion.

\section{Conditioning Regimen and Post-Transplant Outcomes}

All 45 patients received a CBV conditioning regimen without any modifications. The median day to neutrophil engraftment and platelet engraftment was 11 days (range: 9-23) and 13 days (range: 8-36), respectively. Five patients had engraftment syndrome, and all responded to low-dose steroids. All patients had febrile neutropenia, of which 11 (24\%) had an FUO (fever of unknown origin) while others had either a CDI (clinically documented infection), MDI (microbiologically documented infection), or both CDI and MDI. The median day to the onset of fever was 2 days (range: $0-11$ ). The median number of antibiotics used was 4 (range: $1-8$ ), and median days of antibiotic usage was 14 (range: 6-29) days. Empirical antifungal, amphotericin B was used in 15 patients (33\%).

Grade 3-4 mucositis was seen in four patients, and all received total parenteral nutrition. Grade 3/4 diarrhea and CINV (chemotherapy-induced nausea and vomiting) were observed in four and two patients, respectively. Hypokalemia and hypomagnesemia were seen in 18 (40\%) and 11 (25\%) patients, respectively. None of the patients had hemorrhagic cystitis, and no grade 3/4 toxicity was observed in other organs viz. renal, liver, pulmonary, or cardiac. The median duration of stay in the transplant unit was 18 days (range: 10-37). Transplant-related mortality (TRM) at 100 days was $6.6 \%(n=3 ; \mathrm{HL}, 1$ and NHL, 2$)$, the cause of death being severe sepsis for all patients. One patient died before engraftment on $d+20$, and two patients died after engraftment on $d+26$ and $d+78$. - Table 2 presents the data on engraftment kinetics, pattern of infection, and toxicity post-transplant.

\section{Post-Transplant Response}

The post-transplant response was available for 40 (89\%) patients. Post-transplant response assessment was not done in five patients as three died before $d+90$, and two 
Table 1 Baseline clinical, treatment characteristics and pre-transplant disease status in $\mathrm{HL}$ and NHL

\begin{tabular}{|c|c|c|c|c|}
\hline \multicolumn{2}{|c|}{ Features } & Entire Cohort $(N=45)$ & $\mathrm{HL}(N=26)$ & $\mathrm{NHL}(N=19)$ \\
\hline \multicolumn{2}{|c|}{ Age (at transplant) in years } & 30 (6-64 years) & $26(6-47)$ & $38(19-64)$ \\
\hline \multicolumn{2}{|c|}{$\begin{array}{l}\text { Gender } \\
\text { Male } \\
\text { Female }\end{array}$} & $\begin{array}{l}28(62.2 \%) \\
17(37.8 \%)\end{array}$ & $\begin{array}{l}17(65 \%) \\
9(35 \%)\end{array}$ & $\begin{array}{l}11(58 \%) \\
8(42 \%)\end{array}$ \\
\hline \multicolumn{2}{|c|}{ Diagnosis (lymphoma) } & & $26(58 \%)$ & $19(42 \%)$ \\
\hline \multicolumn{2}{|c|}{ Relapsed } & $28(62 \%)$ & $14(54 \%)$ & $14(74 \%)$ \\
\hline \multicolumn{2}{|c|}{ Refractory } & 15 (34\%) & $12(46 \%)$ & $3(16 \%)$ \\
\hline \multicolumn{2}{|c|}{ Upfront (in CR1 for HR) } & $2(4 \%)$ & - & $2(10 \%)$ \\
\hline \multirow[t]{6}{*}{$\mathrm{NHL}$} & Relapsed/refractory DLBCL & - & - & $12(63 \%)$ \\
\hline & ALCL (ALK negative) (upfront) & & & $2(11 \%)$ \\
\hline & Relapsed FL & & & $2(11 \%)$ \\
\hline & Relapsed PTCL & & & $1(5 \%)$ \\
\hline & Relapsed AITL & & & $1(5 \%)$ \\
\hline & Relapsed ALCL & & & $1(5 \%)$ \\
\hline \multicolumn{2}{|c|}{$\begin{array}{l}\text { Time from diagnosis to transplant in months } \\
\text { (median, range) }\end{array}$} & $19(5-102)$ & $21(8-84)$ & $16(5-102)$ \\
\hline \multicolumn{2}{|c|}{ Number of lines of treatment (median, range) } & $2(1-4)$ & $2(1-4)$ & $2(1-3)$ \\
\hline \multicolumn{2}{|c|}{ ECOG PS (median, range) } & $1(0-1)$ & $1(0-1)$ & $1(0-1)$ \\
\hline \multicolumn{5}{|c|}{ Chemosensitivity } \\
\hline \multicolumn{2}{|c|}{ Yes } & $43(95.6 \%)$ & $24(92 \%)$ & $19(100 \%)$ \\
\hline \multicolumn{2}{|l|}{ No } & $2(4.4 \%)$ & $2(8 \%)$ & 0 \\
\hline \multicolumn{5}{|c|}{$\begin{array}{l}\text { Pre-transplant imaging for disease status } \\
\text { PET CT-22 (49\%) } \\
\text { CECT-23 (51\%) }\end{array}$} \\
\hline \multicolumn{5}{|c|}{ PET CT response $(N=22)$} \\
\hline \multicolumn{2}{|c|}{ CR (complete response) } & $15(68 \%)$ & $10(77 \%)$ & $5(55 \%)$ \\
\hline \multicolumn{2}{|c|}{ PR (partial response) } & $7(32 \%)$ & $3(23 \%)$ & $4(45 \%)$ \\
\hline \multicolumn{2}{|c|}{ SD (stable disease) } & 0 & 0 & 0 \\
\hline \multicolumn{2}{|c|}{ PD (progressive disease) } & 0 & 0 & 0 \\
\hline \multicolumn{5}{|c|}{ CECT response $(N=23)$} \\
\hline \multicolumn{2}{|c|}{ CR (complete response) } & $8(35 \%)$ & $5(39 \%)$ & $3(30 \%)$ \\
\hline \multicolumn{2}{|c|}{ PR (partial response) } & $13(56 \%)$ & $6(46 \%)$ & 7 (70\%) \\
\hline \multicolumn{2}{|c|}{ SD (stable disease) } & $1(4.5)$ & $1(7.5 \%)$ & 0 \\
\hline \multicolumn{2}{|c|}{ PD (progressive disease) } & $1(4.5 \%)$ & $1(7.5 \%)$ & 0 \\
\hline
\end{tabular}

Abbreviations: AITL, angioimmunoblastic T cell lymphoma; ALCL, anaplastic large cell lymphoma; CECT, contrast-enhanced computed tomography; DLBCL, diffuse large B cell lymphoma; ECOG PS, Eastern Cooperative Oncology Group-Performance status; FL, follicular lymphoma; HL, Hodgkin lymphoma; NHL, non-Hodgkin lymphoma; PET CT, positron emission tomography and computed tomography; PTCL, peripheral T cell lymphoma.

were lost to follow-up post-ASCT. In the entire cohort, posttransplant CR was observed in $25(62.5 \%)$ patients, PR in 8 (20\%) patients, and progressive disease (PD) in 7 (17.5\%) patients. Change in the disease status from pre-transplant period to post-transplant is shown in the bar diagram in - Fig. 1.

\section{Survival}

The median follow-up for the entire cohort was 44.8 months (95\% CI: 33.8-55.8). The median EFS for the entire cohort was 23.8 months (95\%CI: 0.00-63.68); for HL, the median EFS was not reached, and for NHL, it was 7.97 months (95\%CI: 1.5714.37). Estimated 3-year EFS was $48 \%$ for the entire cohort; for HL and NHL, it was $57.4 \%$ and $33.7 \%$, respectively. The median OS for the entire cohort and for HL was not reached; for NHL, it was 24.3 months (95\%CI: 0.56-48.11). The estimated OS at 3 years was $61.6 \%$ for the entire cohort and $74.6 \%$ and $43.4 \%$ for HL and NHL, respectively.

An association of survival outcomes with respect to baseline features viz. relapsed vs. refractory disease, number of lines of salvage therapy, and pre-transplant disease status, complete response vs. partial response is shown in 
Table 2 Post-transplant engraftment kinetics, pattern of infection, toxicity, and supportive care in $\mathrm{HL}$ and $\mathrm{NHL}$

\begin{tabular}{|c|c|c|c|c|}
\hline & & $\begin{array}{l}\text { Entire } \\
\text { cohort } \\
(N=45)\end{array}$ & $\begin{array}{l}\mathrm{HL} \\
(N=26)\end{array}$ & $\begin{array}{l}\mathrm{NHL} \\
(N=19)\end{array}$ \\
\hline \multirow[t]{2}{*}{$\begin{array}{l}\text { Day of } \\
\text { engraftment }\end{array}$} & Neutrophils & $11(9-23)$ & $\begin{array}{l}11 \\
(9-17)\end{array}$ & $10.5(9-23)$ \\
\hline & Platelets & $13(8-36)$ & $\begin{array}{l}12.50 \\
(8-36)\end{array}$ & $14.5(11-30)$ \\
\hline \multirow{4}{*}{$\begin{array}{l}\text { Febrile } \\
\text { neutropenia }\end{array}$} & FUO & 11 (24\%) & $8(31 \%)$ & $3(16 \%)$ \\
\hline & CDI & $18(40 \%)$ & $9(35 \%)$ & $9(47 \%)$ \\
\hline & MDI & $10(22 \%)$ & $5(19 \%)$ & $5(26 \%)$ \\
\hline & $\begin{array}{l}\mathrm{CDI} \text { and } \\
\mathrm{MDI}\end{array}$ & $6(14 \%)$ & $4(15 \%)$ & $2(11 \%)$ \\
\hline \multicolumn{2}{|c|}{ No of antibiotics } & $4(1-8)$ & $4(2-8)$ & $4(1-7)$ \\
\hline \multirow[t]{5}{*}{ Organism } & Sterile & $26(58 \%)$ & $15(58 \%)$ & $11(58 \%)$ \\
\hline & $\begin{array}{l}\text { Gram } \\
\text { negative }\end{array}$ & $13(30 \%)$ & $6(23 \%)$ & $7(37 \%)$ \\
\hline & $\begin{array}{l}\text { Gram } \\
\text { positive }\end{array}$ & 0 & 0 & 0 \\
\hline & $\begin{array}{l}\text { Polymicro- } \\
\text { bial }\end{array}$ & $5(10 \%)$ & $5(19 \%)$ & 0 \\
\hline & Fungal & $1(2 \%)$ & 0 & $1(5 \%)$ \\
\hline \multirow[t]{3}{*}{ Mucositis } & Grade 0 & $10(22 \%)$ & $3(10 \%)$ & $7(37 \%)$ \\
\hline & Grade1-2 & 31 (69\%) & 19 (76\%) & 12 (63\%) \\
\hline & Grade 3-4 & $4(9 \%)$ & $4(14 \%)$ & 0 \\
\hline \multirow[t]{3}{*}{ CINV } & Grade 0 & $9(20 \%)$ & $4(16 \%)$ & $5(26 \%)$ \\
\hline & Grade 1-2 & $34(66 \%)$ & 20 (77\%) & 14 (74\%) \\
\hline & Grade 3-4 & $2(4 \%)$ & $2(7 \%)$ & 0 \\
\hline \multirow[t]{3}{*}{ Diarrhea } & Grade 0 & $21(47 \%)$ & $13(50 \%)$ & $8(42 \%)$ \\
\hline & Grade 1-2 & $20(43 \%)$ & $10(38 \%)$ & $10(53 \%)$ \\
\hline & Grade 3-4 & $4(10 \%)$ & $3(12 \%)$ & $1(5 \%)$ \\
\hline \multirow[t]{2}{*}{ TPN } & Yes & $4(9 \%)$ & $4(15 \%)$ & - \\
\hline & No & 41 (91\%) & 22 (85\%) & 19 (100\%) \\
\hline \multirow{2}{*}{$\begin{array}{l}\text { Blood } \\
\text { products }\end{array}$} & PRBC & $3(0-8)$ & $3(0-8)$ & $3(0-7)$ \\
\hline & SDP & $4(2-13)$ & $4(2-12)$ & $4(2-13)$ \\
\hline \multicolumn{2}{|c|}{$\begin{array}{l}\text { Length of stay in days } \\
\text { (median, range) }\end{array}$} & $18(10-37)$ & $\begin{array}{l}25 \\
(10-37)\end{array}$ & $18(10-30)$ \\
\hline
\end{tabular}

Abbreviations: CDI, clinically documented infection; CINV, chemotherapy-induced nausea and vomiting; FUO, fever of unknown origin; HL, Hodgkin lymphoma; MDI, microbiologically documented infection; NHL, non-Hodgkin lymphoma; PRBC, packed red blood cells; SDP, single donor platelets; TPN, total parenteral nutrition.

- Supplementary Tables S1 and S2. A comparison of survival outcomes based on the pre-transplant disease status of CR vs. PR in subgroups of HL and NHL, respectively, is shown in - Fig. 2.

\section{Discussion}

The present standard of care for relapsed/refractory lymphoma is HDC followed by ASCT. ${ }^{2,5}$ Several HDC regimens have been in use as conditioning protocol in the autologous transplant of lymphomas, and most have shown similar

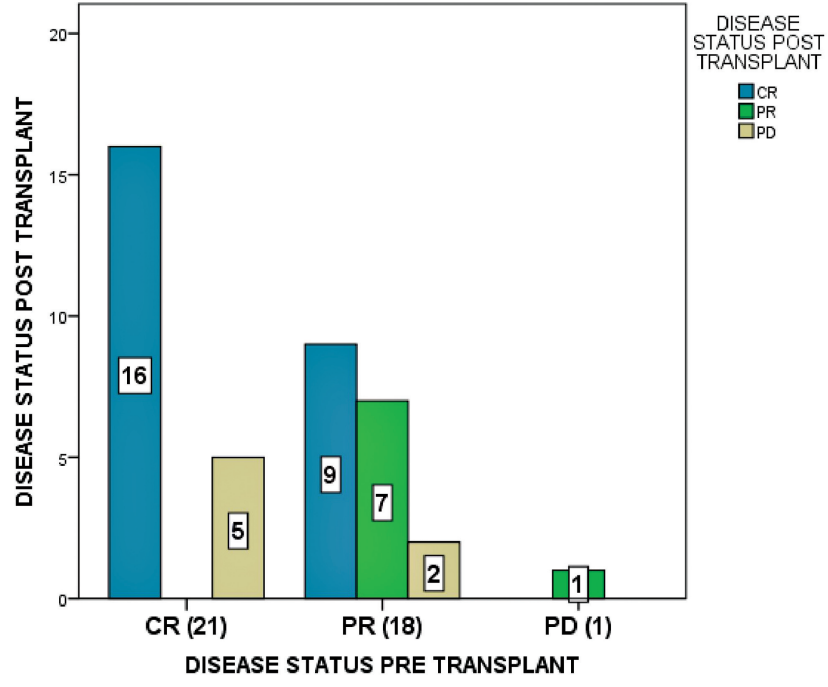

Fig. 1 Comparison of disease status pre and post-transplant in the entire cohort; $C R$, complete response, PR, partial response, PD, progressive disease. $X$ axis indicates disease status pre-transplant and $Y$ axis indicates disease status post-transplant. Among 21 patients who had $C R$ pre transplant, 16 maintained $C R$, and 5 had progressive disease post-transplant. Among the 18 patients who had PR before transplant, 9 achieved CR, 7 maintained PR, and 2 had progressive disease. One patient who had progressive disease pre transplant achieved PR post-transplant.

efficacy but with different toxicity profiles. CBV is one of the older conditioning regimens for lymphoma with a relatively safer toxicity profile, especially with low-dose CBV. Sparse data are available on the contemporary use of CBV, especially from India. Our study found CBV practicable, less toxic, and had efficacy comparable to that reported in the literature for other regimens used in lymphoma conditioning.

We report the results of 45 transplants for $\mathrm{HL}$ and NHL with CBV conditioning. The majority of the patients (95\%) had chemosensitive disease at transplant. Grade 3 or 4 toxicities were observed in only $10 \%$ of our patients, common toxicities being mucositis, diarrhea, and CINV. No grade $3 / 4$ toxicity was observed in other organs viz. renal, liver, pulmonary, or cardiac. Toxicity in our study was comparable to that reported for low-dose CBV. ${ }^{10,11,16}$ Studies with the original CBV (high dose) regimen with BCNU dose of 600 $\mathrm{mg} / \mathrm{m}^{2}$ have reported higher pulmonary toxicity (5-10\%). However, subsequent reports with the use of BCNU at 450 $\mathrm{mg} / \mathrm{m}^{2}$ or $300 \mathrm{mg} / \mathrm{m}^{2}$ (CBV low) have shown less pulmonary toxicity $(<1 \%)$ without any loss of efficacy. ${ }^{10-12,16}$ Also, Chen et al proved that carmustine dose higher than $300 \mathrm{mg} / \mathrm{m}^{2}$ resulted only in increased toxicity without any survival benefit. $^{10}$ Other grade 3 or 4 toxicities with CBV (low) included mucositis in about 8 to $25 \%$, diarrhea 10 to $25 \%$, CINV 4 to $8 \%$ from various studies in the literature. ${ }^{10,14,16} \mathrm{As}$ summarized in $\mathbf{- T a b l e ~} \mathbf{3}$, grade $3 / 4$ regimen-related toxicities were relatively less with CBV (low) compared to other commonly used conditioning regimens such as BEAM, BEAC, or LACE (10-25\% in CBV low vs. $30-55 \%$ in other regimens) although with comparable survival outcomes. 
a)

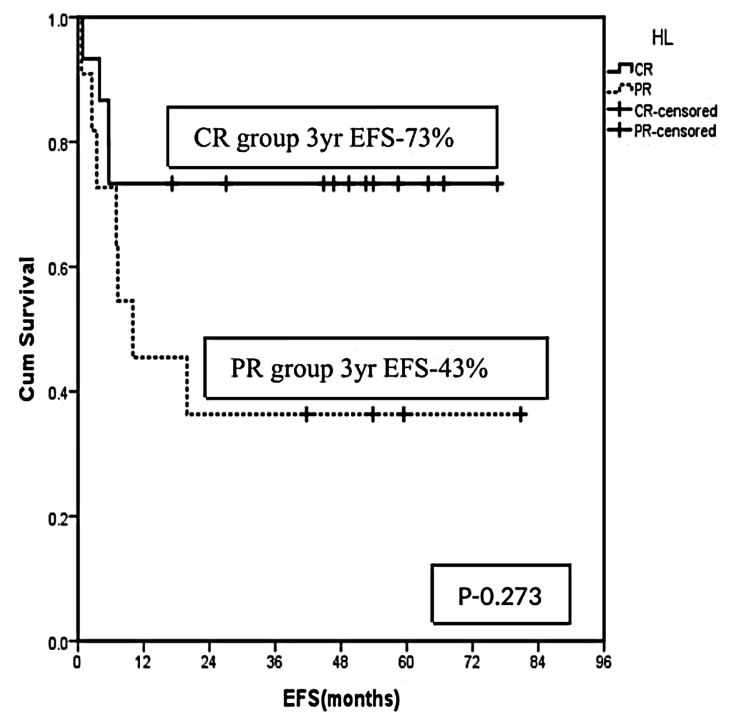

c)

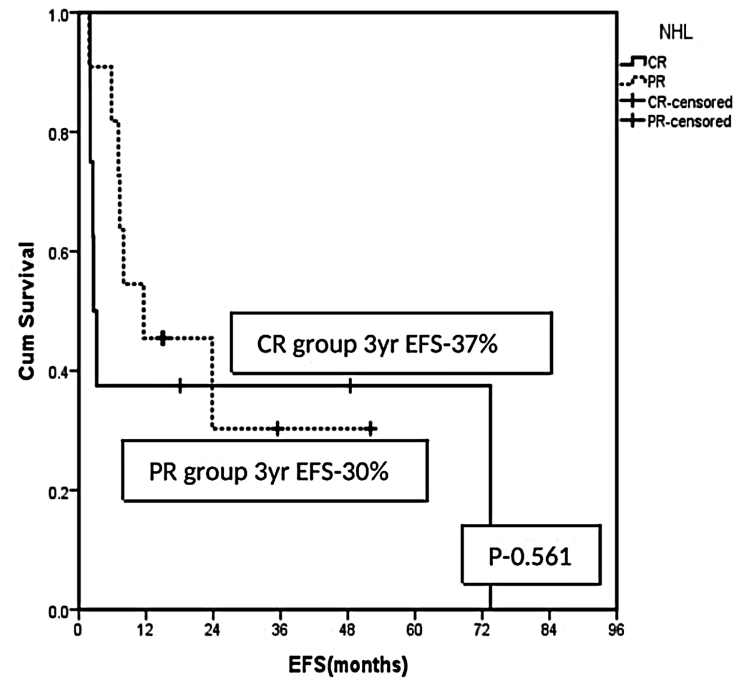

b)

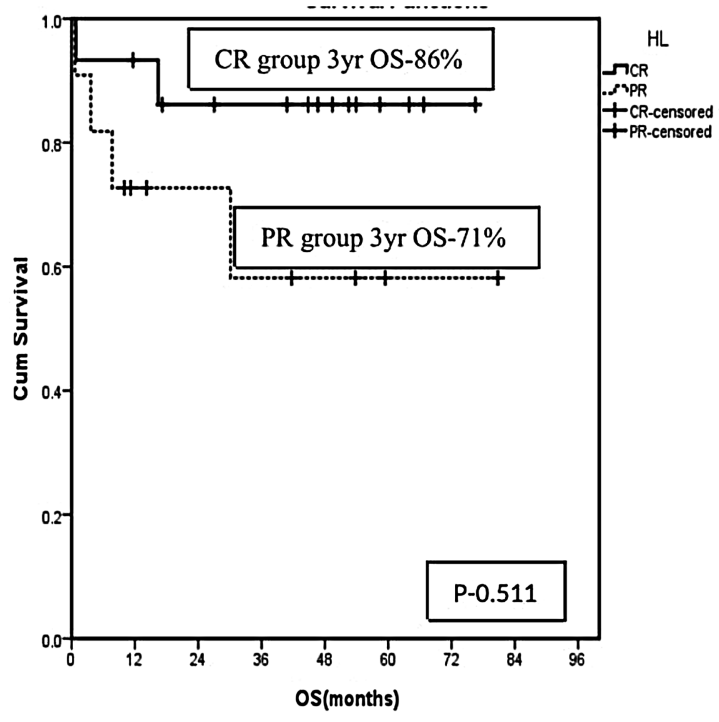

d)

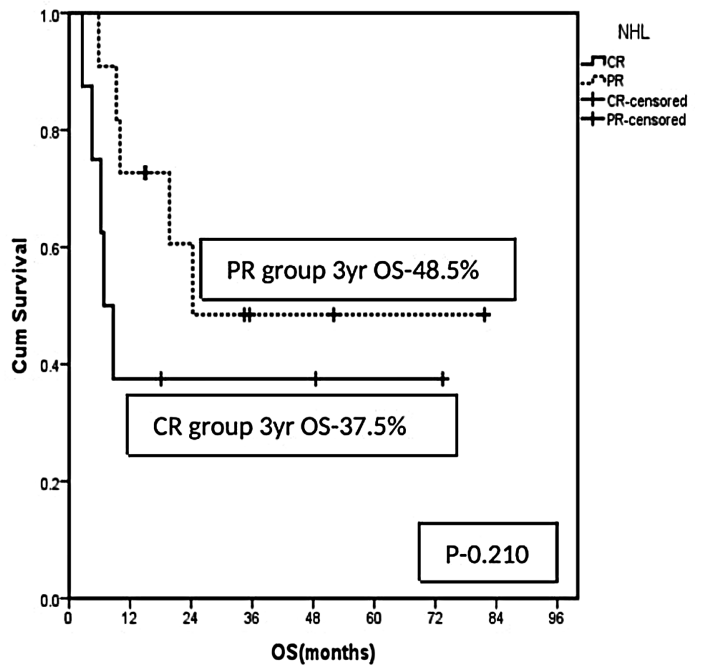

Fig. 2 Kaplan-Meier survival estimate for (A) event-free survival, (B) overall survival for Hodgkin lymphoma, and (C) event-free survival (D) overall survival for non-Hodgkin lymphoma, comparing outcomes with respect to pre-transplant disease status.

The median time to engraftment was 11 days (range: 923 ) and 13 days (range: 8-36) for neutrophils and platelets, respectively. Engraftment time was comparable to results reported with $\mathrm{CBV}$ conditioning and other conditioning regimens. ${ }^{12,13,15,24}$ Post day 0 (stem cell infusion) hospitalization was for 18 days (range: 10-37) in our study, while it ranged from 17 to 25 days in reports of CBV and other regimens from different transplant settings. ${ }^{10,11,13,15}$ During the first 30 days of transplant, PRBC (packed red blood cell) and single donor platelet (SDP) were required for a median of 3 and 4 units, respectively. TPN was used in $7 \%$ of our patients, mostly for moderate to severe mucositis, comparable to published data on TPN use for moderate to severe mucositis during lymphoma ASCT. ${ }^{10,13-15}$ TRM at 100 days was $6.6 \%$ in our cohort comparable to that reported for CBV (7-10\%) in other settings. ${ }^{10,11}$ A relatively higher TRM (13$18 \%$ ) has been reported for other conditioning regimens as BEAM. ${ }^{13,15}$ Overall, from different studies in the literature, as summarized in - Table 3, including ours, CBV has shown a lower incidence of mucositis and other toxicities, lesser requirement for parenteral nutrition, shorter hospital stay, and lower TRM compared to other conventional regimens.

In our study, post-transplant evaluation of response had shown a CR of $62 \%$ and a PR of $20 \%$ compared to $49 \%$ and $47 \%$, respectively, during the pre-transplant assessment. Thus, about $18 \%$ of patients had a progression within 3 months 
CBV in Autologous Stem Cell Transplant in Lymphoma Krishnamoorthi et al.

Table 3 Summary of comparative studies of conditioning regimens for toxicity and survival outcomes in lymphoma

\begin{tabular}{|c|c|c|c|c|c|}
\hline Study & Regimen & Toxicity & TRM (d100-150) & PFS & os \\
\hline $\begin{array}{l}\text { Arranz et al } \\
1997, \text { Spain } \\
\text { HL }(n=49) \\
\text { Retrospective study }\end{array}$ & $\mathrm{CBV}^{\text {high }}$ vs. $C B V^{\text {low }}$ & Not reported & $9 \%$ vs. $8 \%$ & $\begin{array}{l}47 \% \text { vs. } 29 \% \\
(p=0.57)\end{array}$ & Not reported \\
\hline $\begin{array}{l}\text { Salar et al, 2001, } \\
\text { Spain }{ }^{3} \\
\text { NHL }(n=395) \\
\text { Retrospective study }\end{array}$ & CBV vs. BEAM vs. CyTBI & Not reported & Not reported & $\begin{array}{l}\text { CBV vs. BEAM } \\
\text { Relative risk } \\
1.26(0.77-2.05) \\
(p=0.34)\end{array}$ & $\begin{array}{l}\text { CBV vs. BEAM } \\
\text { Relative risk } \\
1.30(0.74-2.28) \\
(p=0.36)\end{array}$ \\
\hline $\begin{array}{l}\text { Puig et al, 2005, } \text { Spain }^{12} \\
(n=113) \\
\text { NHL }(n=69) \\
\text { HL }(n=44) \\
\text { Retrospective study }\end{array}$ & CBV high vs. BEAM & $\begin{array}{l}\text { Mucositis (grade } 1-2 \text { ) } \\
6 \% \text { vs. } 34 \% \\
\text { Pulmonary (grade } 3 \text { ) } \\
4 \% \text { vs. } 0 \% \\
\text { SOS: } 5 \% \text { vs. } 0 \%\end{array}$ & $24 \%$ vs. $5 \%$ & Not reported & Not reported \\
\hline $\begin{array}{l}\text { Harris et al, } \\
\text { COG A5962, 2011, USA } 16 \\
\text { HL }(n=28) \\
\text { NHL }(n=10) \\
\text { Prospective study }\end{array}$ & $\begin{array}{l}\text { CBV single arm study } \\
\text { CBV }^{\text {high }}: 450 \mathrm{mg} / \mathrm{m} 2 \\
\text { CBV }^{\text {low }}: 300 \mathrm{mg} / \mathrm{m} 2\end{array}$ & $\begin{array}{l}\text { CBVhigh vs. CBVlow } \\
\text { Pulmonary toxicity } \\
\text { (grade } 3 / 4 \text { ) } \\
100 \% \text { vs. } 0 \%\end{array}$ & Not reported & $\begin{array}{l}\text { 3year EFS } \\
\text { HL: } 45 \% \\
\text { NHL: } 30 \%\end{array}$ & $\begin{array}{l}\text { 3year OS } \\
\text { HL:63\% } \\
\text { NHL:34\% }\end{array}$ \\
\hline $\begin{array}{l}\text { Sharma et al, } 2013 \\
\text {, India }{ }^{15}(n=51) \\
\text { NHL }(n=26) \\
\text { HL }(n=25) \\
\text { Retrospective study }\end{array}$ & BEAM vs. LEAM & $\begin{array}{l}\text { Mucositis (grade } 3 / 4 \text { ) } \\
68 \% \text { vs. } 65 \% \\
\text { Diarrhea (grade } 3 / 4 \text { ) } \\
47 \% \text { vs. } 41 \%\end{array}$ & $18 \%$ vs. $12 \%$ & $\begin{array}{l}2 \text { year EFS } \\
(\mathrm{HL}+\mathrm{NHL}) \\
44.6 \% \text { vs. } 41.1 \% \\
(p=0.510)\end{array}$ & $\begin{array}{l}2 \text { year OS } \\
(\mathrm{HL}+\mathrm{NHL}) \\
61.7 \% \text { vs. } 62.7 \% \\
(p=0.928)\end{array}$ \\
\hline $\begin{array}{l}\text { Chen et al, } 2015, \\
\text { Multicenter study } \\
(n=4,917) \\
\text { NHL }(n=3,905) \\
\text { HL }(n=1,012) \\
\text { Retrospective study }\end{array}$ & $\begin{array}{l}\text { CBVhigh vs. CBV low vs. } \\
\text { BEAM vs. BuCy vs. TBI }\end{array}$ & $\begin{array}{l}\text { CBV high vs. CBV } \\
\text { vs. BEAM } \\
\text { Overall toxicity } \\
\text { (grade } 3-4 \text { ) } \\
6 \% \text { vs. } 3 \% \text { vs. } 3 \%\end{array}$ & Not reported & $\begin{array}{l}\text { CBVhigh vs. CBV low } \\
\text { vs. BEAM } \\
3 \text { year PFS } \\
\text { HL } \\
57 \% \text { vs. } 60 \% \text { vs. } 62 \% \\
\text { DLBCL } \\
39 \% \text { vs. } 47 \% \text { vs. } 47 \%\end{array}$ & $\begin{array}{l}\text { CBV high vs. CBV low } \\
\text { vs. BEAM } \\
3 \text { year OS } \\
\text { HL } \\
68 \% \text { vs. } 73 \% \text { vs. } 78 \% \\
\text { DLBCL } \\
43 \% \text { vs. } 55 \% \text { vs. } 58 \%\end{array}$ \\
\hline $\begin{array}{l}\text { Khattry et al } \\
2016, \text { India }^{13} \\
(\mathrm{~N}=139) \\
\mathrm{NHL}=92 \\
\mathrm{HL}=47 \\
\text { Retrospective study }\end{array}$ & LACE vs. BEAM & $\begin{array}{l}\text { Mucositis (grade } 3-4 \text { ) } \\
8 \% \text { vs. } 38 \%\end{array}$ & $9 \%$ vs. $13 \%$ & $\begin{array}{l}\text { 5-year PFS } \\
\text { HL: } \\
39 \% \text { vs. } 48 \% \\
(p=0.747) \\
\text { NHL: } \\
34 \% \text { vs. } 46 \% \\
(p=0.709)\end{array}$ & $\begin{array}{l}\text { 5-year OS } \\
\text { HL: } \\
49 \% \text { vs. } 48 \% \\
p=0.279 \\
\text { NHL } \\
37 \% \text { vs. } 46 \% \\
(p=0.709)\end{array}$ \\
\hline $\begin{array}{l}\text { SHI et al } \\
2016, \text { China }^{14} \\
\text { NHL }(n=129) \\
\text { Retrospective study }\end{array}$ & CBV vs. BEAM vs. BEAC & $\begin{array}{l}\text { CBV vs. BEAM } \\
\text { Diarrhea( } \geq \text { grade } 2) \\
18.8 \% \text { vs. } 63.9 \% \\
\text { Mucositis ( } \geq \text { grade } 2) \\
25 \% \text { vs. } 47.2 \%\end{array}$ & $0 \%$ & $\begin{array}{l}\text { CBV vs. BEAM vs. BEAC } \\
5 \text {-year EFS } \\
43.8 \% \text { vs. } 66.7 \% \text { vs. } 67.5 \% \\
(p=0.40)\end{array}$ & $\begin{array}{l}\text { CBV vs. BEAM vs. } \\
\text { BEAC } \\
5 \text {-year OS } \\
68.8 \% \text { vs. } 77.8 \% \\
\text { vs. } 81.8 \% \\
(p=0.584)\end{array}$ \\
\hline $\begin{array}{l}\text { Our study }(N=45) \\
\mathrm{HL}=26 \\
\mathrm{NHL}=19 \\
\text { Retrospective study }\end{array}$ & CBV-single arm & $\begin{array}{l}\text { Diarrhea (grade } 3 / 4 \text { ) } \\
10 \% \\
\text { Mucositis (grade 3/4) } \\
9 \%\end{array}$ & $6.6 \%$ & $\begin{array}{l}\text { 3-year EFS } \\
\text { HL 57.4\% } \\
\text { NHL 33.7\% }\end{array}$ & $\begin{array}{l}\text { 3-year OS } \\
\text { HL 74.6\% } \\
\text { NHL } 43.4 \%\end{array}$ \\
\hline
\end{tabular}

Abbreviations: BEAC, BCNU, etoposide, cytarabine and cyclophosphamide; BEAM, BCNU, etoposide, cytarabine, and melphalan; CBV, cyclophosphamide, BCNU and etoposide; DLBCL, diffuse large B cell lymphoma; HL, Hodgkin lymphoma; LACE, lomustine, etoposide, cytarabine, and cyclophosphamide; NHL, non-Hodgkin lymphoma; OS, overall survival; PFS, progression-free survival; SOS, sinusoidal obstruction syndrome; TBI, total body irradiation; TRM, treatment-related mortality.

of transplant, indicating a high-risk subset who had progressed despite having a chemosensitive disease. There is scant literature on the evaluation of disease response in the immediate post-transplant period as the majority of the studies on autologous transplant in lymphoma describe efficacy outcomes in terms of DFS and OS. Nevertheless, besides chemosensitivity of the disease pre-transplant, other risk factors for progression need further evaluation in a larger cohort.

The median EFS in our cohort was 23.8 months, and the median OS was not reached. As shown in - Table 3, our outcomes were comparable to those reported in the literature for CBV and other regimens for HL and NHL transplants. We observed that patients who had received more than two lines of salvage treatment and patients in PR before transplant had inferior EFS and OS although statistically not significant. In the subset of $\mathrm{HL}$, patients having CR pretransplant had higher 3-year EFS and OS (73\% and 86\%, respectively) than patients in PR (43\% EFS and 71\% OS) although statistically not significant. In the NHL subset, no statistically significant difference was seen in 3-year EFS or OS for patients having CR (37\% and 37.5\%, respectively) or PR 
(30\% and $48.5 \%$, respectively) pre-transplant. In several studies in the literature, CR pre-transplant has been shown to be a predictor for better EFS, DFS, and OS in both HL and NHL. ${ }^{25,26}$ We did not find any significant difference between patients in CR or PR, possibly due to the small sample size and short follow-up.

Our results and a review of the literature suggest that CBV (low) is generally a safe conditioning regimen with lower toxicities and similar efficacy compared to other conventional regimens, viz. BEAM, BEAC, LACE, or LEAM, especially for patients with HL. However, prospective randomized studies are needed with a larger cohort of patients to know the difference in toxicities and outcomes with various conditioning regimens for lymphoma. Our analysis had limitations inherent to a retrospective study. We had a small number of patients and short follow-up, which precluded any meaningful interpretation of the factors affecting the outcome. Nevertheless, this is the first study from India to report the toxicity profile and efficacy of CBV conditioning.

\section{Conclusion}

CBV (low) is relatively safe, with common toxicities being mucositis, diarrhea, CINV, and overall grade 3/4 toxicities experienced by less than $10 \%$ of patients. Thus, CBV can be a preferred regimen in resource-limited settings. Event-free survival and overall survival with CBV were comparable to that reported in the literature, especially for patients with Hodgkin lymphoma.

\section{Authors' Contributions \\ Study conceptualization and methodology: SK, NK, BP, DK, $\mathrm{CK}$, and BD. Data collection and analysis: NK, SK, BP, DK, CK, KR, and MR. Manuscript writing: NK, BP, SK, and PG. Review and editing: SK, BD, and PG. Final approval of manuscript: all authors.}

\section{Funding}

None.

\section{Conflict of Interest \\ None declared.}

\section{Acknowledgments}

We acknowledge the contribution of JIPMER (Jawaharlal Institute of Postgraduate Medical Education and Research) for providing logistic support for this work. We also recognize the contribution of all the staff and residents of the BMT unit toward dedicated patient care and maintenance of clinical records.

\section{References}

1 Philip T, Biron P. High-dose chemotherapy and autologous bone marrow transplantation in diffuse intermediate- and high-grade non-Hodgkin lymphoma. Crit Rev Oncol Hematol 2002;41(02): 213-223

2 Sureda A, Bader P, Cesaro S, et al. Indications for allo- and auto-SCT for haematological diseases, solid tumours and immune disor- ders: current practice in Europe, 2015. Bone Marrow Transplant 2015;50(08):1037-1056

3 Salar A, Sierra J, Gandarillas M, et al; GEL/TAMO Spanish Cooperative Group. Autologous stem cell transplantation for clinically aggressive non-Hodgkin's lymphoma: the role of preparative regimens. Bone Marrow Transplant 2001;27(04):405-412

4 Mounier N, Gisselbrecht C. Conditioning regimens before transplantation in patients with aggressive non-Hodgkin's lymphoma. Ann Oncol 1998;9(Suppl 1):S15-S21

5 Philip T, Guglielmi C, Hagenbeek A, et al. Autologous bone marrow transplantation as compared with salvage chemotherapy in relapses of chemotherapy-sensitive non-Hodgkin's lymphoma. N Engl J Med 1995;333(23):1540-1545

6 Isidori A, Christofides A, Visani G. Novel regimens prior to autologous stem cell transplantation for the management of adults with relapsed/refractory non-Hodgkin lymphoma and Hodgkin lymphoma: alternatives to BEAM conditioning. Leuk Lymphoma 2016;57(11):2499-2509

7 Philip T, Chauvin F, Bron D, et al. PARMA international protocol: pilot study on 50 patients and preliminary analysis of the ongoing randomized study (62 patients). Ann Oncol 1991;2 (Suppl 1):57-64

8 Rajamanickam D, Gokarn A, Gupta A, et al. LACE - an effective conditioning regimen for lymphoma patients undergoing autologous transplant- analysis of outcomes and prognostic factors. J Cancer Res Ther 2018;14(05):926-933

9 Galieni P, Troiani E, Bigazzi C, et al. Modified BEAM as conditioning regimen for lymphoma patients undergoing autologous hematopoietic stem cell transplantation. Bone Marrow Transplant 2018; 53(01):91-93

10 Chen Y-B, Lane AA, Logan B, et al. Impact of conditioning regimen on outcomes for patients with lymphoma undergoing high-dose therapy with autologous hematopoietic cell transplantation. Biol Blood Marrow Transplant 2015;21(06):1046-1053

11 Arranz R, Tomás JF, Gil-Fernández JJ, et al. Autologous stem cell transplantation (ASCT) for poor prognostic Hodgkin's disease (HD): comparative results with two CBV regimens and importance of disease status at transplant. Bone Marrow Transplant 1998;21(08):779-786

12 Puig N, de la Rubia J, Remigia MJ, et al. Morbidity and transplantrelated mortality of $\mathrm{CBV}$ and BEAM preparative regimens for patients with lymphoid malignancies undergoing autologous stem-cell transplantation. Leuk Lymphoma 2006;47(08): 1488-1494

13 Khattry N, Gupta A, Jain R, et al. LACE versus BEAM conditioning in relapsed and refractory lymphoma transplant: retrospective multicenter analysis of toxicity and efficacy. Int J Hematol 2016;103(03):292-298

14 Shi Y, Liu P, Zhou S, et al. Comparison of CBV, BEAM and BEAC high-dose chemotherapy followed by autologous hematopoietic stem cell transplantation in non-Hodgkin lymphoma: efficacy and toxicity. Asia Pac J Clin Oncol 2017;13(05):e423-e429

15 Sharma A, Kayal S, Iqbal S, Malik PS, Raina V. Comparison of BEAM vs. LEAM regimen in autologous transplant for lymphoma at AIIMS. Springerplus 2013;2:489

16 Harris RE, Termuhlen AM, Smith LM, et al. Autologous peripheral blood stem cell transplantation in children with refractory or relapsed lymphoma: results of Children's Oncology Group study A5962. Biol Blood Marrow Transplant 2011;17(02): 249-258

17 Colby C, McAfee SL, Finkelstein DM, Spitzer TR. Early vs delayed administration of G-CSF following autologous peripheral blood stem cell transplantation. Bone Marrow Transplant 1998;21(10): 1005-1010

18 de Azevedo AM, Nucci M, Maiolino A, et al. A randomized, multicenter study of G-CSF starting on day +1 vs day +5 after autologous peripheral blood progenitor cell transplantation. Bone Marrow Transplant 2002;29(09):745-751 
19 Valcárcel D, Sureda A. Graft failure. In: Carreras E, Dufour C, Mohty M, Kröger N, eds. The EBMT Handbook: Hematopoietic Stem Cell Transplantation and Cellular Therapies. 7th ed. Springer; 2019: 307-313

20 Murray S. Engraftment. In: Maziarz RT, Slater SS, eds. Blood and Marrow Transplant Handbook: Comprehensive Guide for Patient Care. Springer International Publishing; 2015:161-165

21 Maiolino A, Biasoli I, Lima J, Portugal AC, Pulcheri W, Nucci M. Engraftment syndrome following autologous hematopoietic stem cell transplantation: definition of diagnostic criteria. Bone Marrow Transplant 2003;31(05):393-397

22 Bearman SI, Appelbaum FR, Buckner CD, et al. Regimen-related toxicity in patients undergoing bone marrow transplantation. J Clin Oncol 1988;6(10):1562-1568

23 Common Terminology Criteria for Adverse Events (CTCAE) । Protocol Development | CTEP. Accessed October 18, 2021 at: https://ctep.cancer.gov/protocoldevelopment/electronic_ applications/ctc.htm

24 Dos Santos KB, Costa LJM, Bettarello G, et al. LEAM versus CBV for conditioning in autologous hematopoietic stem cell transplantation for lymphoma. Bone Marrow Transplant 2019;54(04): 625-628

25 Bishop MR, Dean RM, Steinberg SM, et al. Correlation of pretransplant and early post-transplant response assessment with outcomes after reduced-intensity allogeneic hematopoietic stem cell transplantation for non-Hodgkin's lymphoma. Cancer 2010;116 (04):852-862

26 Nieto Y, Popat U, Anderlini P, et al. Autologous stem cell transplantation for refractory or poor-risk relapsed Hodgkin's lymphoma: effect of the specific high-dose chemotherapy regimen on outcome. Biol Blood Marrow Transplant 2013;19(03): $410-417$ 